\title{
LA FUNCIÓN NOTARIAL EN LAS SENTENCIAS DEL TRIBUNAL CONSTITUCIONAL
}

\author{
OSWALdO ARIAS MONTOYA* \\ Universidad de Lima, Lima, Perú \\ oarias@ulima.edu.pe \\ Recibido: 11/11/2020 Aprobado:18/11/2020 \\ doi: https://doi.org/10.26439/iusetpraxis2021.n052.4948
}

\begin{abstract}
RESUMEN. El presente artículo revisa siete sentencias del Tribunal Constitucional que establecen criterios regulatorios de la función notarial en el Perú. Entre los aspectos tratados por el órgano supremo de la jurisdicción constitucional, están los referidos al acceso a la información pública custodiada por el notario, la conducta ejemplar del notario en la defensa de sus derechos, los límites a la adopción de extranjeros tramitada ante notario, la función del notario en materia de certificación de autenticidad de reproducciones, la custodia y conservación del protocolo, la responsabilidad del notario en los casos de fraudes documentarios y suplantaciones de identidad, y la relación entre la autoridad estatal y la libertad gremial de los notarios.
\end{abstract}

PALABRAS CLAVE: notario / función notarial / seguridad jurídica

\section{THE NOTARIAL FUNCTION IN THE PERUVIAN CONSTITUTIONAL COURT JUDGMENTS}

ABSTRACT. This article reviews seven judgments on regulatory criteria for the notarial function in Peru handed down by the Peruvian Constitutional Court. Among the aspects dealt with by the highest governing body of constitutional jurisdiction are those concerning the access to public records kept by notaries, the exemplary conduct of notaries in defense of people's rights, the restrictions on the adoption of foreigners handled through a notary, the function of notaries in terms of certification of authenticity for reproductions, the custody and preservation of the protocol, the responsibility of the notary in cases of documentary fraud and identity theft, and the relationship between the state authority and the trade union freedom of notaries.

KEYWORDS: notary / notarial function / legal certainty

\footnotetext{
* Notario de Lima. Doctor en Derecho y Ciencia Política por la Universidad Nacional Mayor de San Marcos.
} 


\section{INTRODUCCIÓN}

El presente artículo puede considerarse una continuación del que publiqué en el año 2011 titulado "Los principios notariales y la Constitución" en mi libro Comentarios a la actualidad notarial peruana. Como en aquel trabajo, me propongo en este seguir dando cuenta argumentada de sentencias del Tribunal Constitucional que son relevantes para el ejercicio de la función notarial en el Perú. De las sentencias que se reseñan y comentan, queda claro que la presencia del notario en nuestra patria no solo es indispensable, como garante de la seguridad jurídica en cuanto redactor imparcial y formalizador de la voluntad de las partes en títulos fehacientes, sino que es altamente beneficiosa para la defensa de los derechos de las personas y el cumplimiento de las normas de orden público que afirman nuestra opción de hacer de nuestra patria un espacio de desarrollo de nuestros proyectos de vida, en armonía con los demás peruanos. Así, sin duda, dejo expresa constancia de la condición del notario en cuanto verdadero magistrado de la paz y arquitecto de la justicia preventiva.

Sentencia de fecha 30 de enero del 2014, recaída en el Expediente N. ${ }^{\circ}$ 06227-2013$\mathrm{PHD} / \mathrm{TC}$, que declara fundada la demanada de habeas data interpuesta por don Samuel Luis Orellana Julián contra don Jorge Alejandro Lazo Villanueva, notario de Chanchamayo

El demandante Samuel Luis Orellana Julián demanda que el notario le otorgue lo siguiente: copias certificadas de una minuta que ha dado origen a la extensión de una escritura pública, testimonio de dicha escritura que corre en el registro de escrituras públicas del notario, así como el documento nacional de identidad (se entiende copia) presentado por la compareciente al momento de la suscripción de dicho instrumento público.

El Tribunal Constitucional, en su fundamento 12, considera que el notario "se ha negado de manera categórica a entregar la información requerida a pesar de que, como lo reconoce en la contestación de la demanda, [...] son instrumentos públicos". No olvidemos que la información del archivo oficial del notario es pública y que, tal como lo establece el artículo 82 del Decreto Legislativo del Notariado, "[e]l notario expedirá, bajo responsabilidad, testimonio, boleta y partes, a quien lo solicite, de los instrumentos públicos notariales que hubiera autorizado en el ejercicio de su función. Asimismo, expedirá copias certificadas de las minutas que se encuentren en su archivo notarial". Es de resaltar lo que señala el Tribunal Constitucional en el fundamento 14, al precisar que el notario emplazado

ha actuado de manera impropia [...]. No solo ha vulnerado el derecho de acceso a la información pública al obligarlo a tener que litigar [...], sino que su defensa se ha basado en hechos falsos. Tal comportamiento no guarda armonía con la conducta ejemplar que un notario público debe tener. 
Por ello se le impondrá una severa multa, en solidaridad con el abogado patrocinante, por haber procedido de manera desleal y maliciosa.

De forma indirecta, en esta sentencia se remarca que se espera del notario un comportamiento "ejemplar", incluso en la defensa de sus derechos, lo que, aunque en este caso no se cumplió, no deja de poner en realce la importancia de la función notarial como paradigma del cumplimiento deontológico de los principios profesionales y morales. Sobre la exigencia de que la conducta del notario, incluso cuando no está desempeñando directamente su función, sea realmente ejemplar, cabe citar a Becerra Palomino (2015):

[...] quien asuma el compromiso de ser notario en nuestro sistema jurídico debe estar consciente de que la connotación público-privada de su actividad le dará una notable fuerza, pero al mismo tiempo lo pondrá en una situación de vulnerabilidad permanente; estará sujeto a la observación constante de la gente no solo en su actividad pública, sino también en sus actos privados, en su vida personal, familiar y social. (p. 424)

Sentencia de fecha 10 de diciembre del 2015, recaída en el Expediente N.$^{\circ} 07977$ 2013-PH/TC, que declaró improcedente la demanda de habeas corpus interpuesta por don Giolmer Genaro Ceclén Morillas a favor de Hanxing Zhong contra el Reniec

En este habeas corpus, se pretendió que el Registro Nacional de Identificación y Estado Civil (Reniec) inscribiese la adopción de don Hanxing Zhong, expidiese una nueva acta de nacimiento, así como su documento nacional de identidad (DNI).

Se refiere que, ante notario de la ciudad de Trujillo, se realizó el trámite de adopción de persona mayor de edad a favor del demandante (ciudadano chino), pero el Reniec negó dicha adopción por contravenir lo dispuesto en el artículo 379 del Código Civil, esto es, por no tener inscrito su nacimiento en el Registro de Estado Civil dentro del Perú, ni en algún Registro de Estado Civil del Consulado Peruano.

Se entiende de ello que, conforme a la interpretación del Reniec, no resulta posible jurídicamente la adopción de un extranjero que nunca haya tenido inscripción previa en el Registro del Estado Civil peruano. El artículo 379 del Código Civil, si bien no tiene una regla de competencia explícita sobre tal situación, señala: “Terminado el procedimiento, [...] el notario, que tramitó la adopción, oficiará al Registro del Estado Civil donde se inscribió el nacimiento [...]". Es decir que, para el Reniec, si no existe una inscripción previa del nacimiento en el Registro del Estado Civil, no es posible una adopción, dado que al término del procedimiento no sería posible inscribir el acto, forzando una inscripción del nacimiento que debió ser previa.

Cabe comentar que, de haber prevalecido la inscripción de la adopción, se habría creado un camino alternativo a la naturalización de los extranjeros como procedimiento 
de adquisición de la nacionalidad peruana, lo que devendría en un fraude a la ley. Peralta Castellano (2013, pp. 255-259) detalla con precisión y rigor los supuestos legalmente establecidos que permiten adquirir la nacionalidad peruana, y entre ellos no aparece -obviamente- la adopción por un peruano.

El Tribunal Constitucional ha acogido en la sentencia reseñada este criterio, precisando, además, que se habría contravenido el artículo 4 del Decreto Legislativo N. ${ }^{0} 1049$, Decreto Legislativo del Notariado, que establece que el ámbito territorial de la competencia notarial es provincial, por lo que, tratándose de la adopción de extranjeros, no es posible aplicar la regla del domicilio del solicitando (en este caso, del adoptado). No debemos olvidar que el artículo 4 de la Ley N. ${ }^{\circ}$ 26662, Ley de Competencia Notarial en Asuntos No Contenciosos, remarca que el notario debe ceñirse rigurosamente al cumplimiento de las normas de orden público en estos procedimientos, pues de no hacerlo así incurriría en responsabilidad conforme al Decreto Legislativo del Notariado y, a partir de la interpretación acogida por el Tribunal Constitucional, los notarios debemos abstenernos de dar trámite a solicitudes como la que dio origen a la sentencia en comentario.

Sentencia de fecha 4 de abril del 2019, recaída en el Expediente N. ${ }^{\circ}$ 06001-2014PA/TC, que declaró infundada la demanda de amparo interpuesta por don Edmundo Cotrina Alfaro contra la AFP Prima, la Oficina de Normalización Previsional y la Superintendencia de Banca, Seguros y Administradoras Privadas de Fondos de Pensiones

En este proceso, el demandante, para acreditar sus derechos pensionarios, acompañó diversos certificados de trabajo y liquidaciones de beneficios sociales. Sin embargo, se determinó por dictamen pericial de grafotecnia de la Dirección de Criminalística de la Policía Nacional del Perú que se trataba de documentos que el Tribunal Constitucional consideró fraudulentos, "pese a lo cual cuenta con la certificación de los notarios públicos César Sánchez Baiocchi, Walter Ricardo Díaz Cárdenas y Gino Barnuevo Cuéllar".

En tal sentido, el Tribunal Constitucional señala en el considerando 15 que "[...] los cuestionados documentos cuentan con la legalización de los notarios públicos César Sánchez Baiocchi, Walter Ricardo Díaz Cárdenas y Gino Barnuevo Cuéllar, se deberá oficiar al Consejo del Notariado y a los Colegios de Notarios de Ica y Callao, a fin de que investiguen los hechos expuestos".

Lamentablemente, en la sentencia no se indica qué tipo de certificación extraprotocolar es la que realizaron los notarios mencionados, pero, por el tenor de los documentos (certificados de trabajo y liquidaciones de beneficios sociales), parece que se trató de certificaciones de reproducciones, en las que, conforme lo establece el artículo 110 del Decreto Legislativo del Notariado, el notario certificará reproducciones de documentos 
obtenidos por cualquier medio idóneo, autorizando con su firma que la copia que se le presenta guarda absoluta conformidad con el original.

Resulta erróneo, entonces, que - de ser este el caso- se considere que pueda existir alguna responsabilidad de los notarios que certificaron copias de documentos que se les exhibieron como originales, si estos habían sido confeccionados fraudulentamente (en la sentencia se señala que las firmas eran "fotocomposiciones"), pues la labor del notario en tales instrumentos protocolares no se refiere a la fiscalización de la autenticidad del documento, sino a la conformidad entre el original y la copia que se certifica. Bien señala Giménez Arnau (1976) hablando de lo que en el Perú se conoce coloquialmente como "copias legalizadas", y que este autor designa como "testimonios por exhibición", que en ellas "garantiza la fe notarial la correspondencia o exactitud entre lo testimoniado y el testimonio, pero sin hacer calificación alguna respecto al contenido, autenticidad de las firmas - si las tuvieran los documentos testimoniadosy capacidad de los firmantes" (p. 793).

De todas formas, es regla de prudencia examinar con cuidado los documentos que se exhiben como originales, para observar si se aprecia alguna grave irregularidad a simple vista, la cual no debe ser pasada por alto por el notario al momento de ejercer su función certificadora.

Sentencia de fecha 21 de noviembre del 2017, recaída en el Expediente N ${ }^{\circ} 03025$ 2014-PHD/TC, que declara infundada la demanda de habeas data interpuesta por don Elías Gregorio Cruz Ormeño contra el notario de Ica Gino Emilio Ernesto Barnuevo Cuéllar

El demandante solicitó al notario "copia fotostática certificada" de una escritura pública de compraventa, pero el notario ofreció entregarle un testimonio en la modalidad de transcripción de dicho instrumento público. Por ello, consideró vulnerado su derecho a acceso a la información pública.

El notario señaló que no entregó lo solicitado porque el tomo donde obraba la escritura pública se encontraba empastado, pero aceptó que el demandante tomara fotografías de la minuta, sus anexos y de la propia escritura pública.

El Tribunal Constitucional, como argumento central para desestimar la demanda, hace una importante reflexión sobre el papel del notario en cuanto custodio de información pública. Así, en el fundamento 8 , indica textualmente:

En relación con el deber del notario como custodio de información pública, debe tenerse presente la labor que él desempeña. Así, conforme a lo estipulado en la normativa vigente, un notario está autorizado para dar fe de los actos y contratos que ante él se celebran. A tal efecto, se encuentra obligado a conservar los 
originales de los documentos o instrumentos en los que se materializan dichos actos. Siendo así, tiene el deber de contar con una infraestructura óptima para la adecuada conservación del acervo documentario que custodia. Precisamente por ello, la formación de tomos es una obligación legal, atendiendo al deber de custodia en óptimas condiciones de los instrumentos públicos. Por lo tanto, la negativa del demandado se encuentra plenamente justificada.

Sabemos que una nota característica asociada a la figura del notario latino es la de custodio del protocolo, conservando de esta forma una matriz de los actos y negocios jurídicos ante él formalizados solemnemente. En este sentido, esta jurisprudencia es importante en nuestro medio para que los notarios tengamos respaldo en nuestra defensa de la integridad del protocolo y su adecuada conservación. Indica Sanahuja y Soler (1945): "Efectivamente, con las reglas que se dictan para la formación y conservación del protocolo se hace mucho más difícil la suplantación de documentos autorizados y la intercalación entre los que ya constan ordenados y fechados". El mismo autor dice más adelante:

[...] para la guarda y custodia del conjunto de documentos que llamamos protocolo, es preciso que el mismo esté a cargo de una persona de gran discreción y moralidad, pues se constituye en depositario de documentos que afectan al bienestar y honor de las personas, y también que sea una persona que sepa cuáles son los derechos que en tales documentos corresponden a los particulares que soliciten los servicios del protocolo. (p. 168)

Subyace otro tema que no ha sido tratado directamente; en apariencia, la exigencia del demandante es la de contar con testimonio obtenido por fotocopia y no por transcripción, aparentemente para comprobar la autenticidad de las firmas en el instrumento público. El artículo 86 del Decreto Legislativo del Notariado es muy claro al señalar que el testimonio, boleta y parte podrá expedirse, a elección del notario, a manuscrito, mecanografiado, en copia fotostática y por cualquier medio idóneo de reproducción. De esta forma, el notario cumplió con su obligación legal y, en todo caso, la determinación de la autenticidad de las firmas del compareciente tendría que hacerse por un perito nombrado por un juez, quien revise el protocolo mismo, cumpliendo las medidas de seguridad que el notario estableciera para fines de su conservación y cuidado.

Sentencia de fecha 11 de diciembre del 2018, recaída en el Expediente N. ${ }^{\circ}$ 02111-2016PA/TC, que declara infundada la demanda de amparo contra amparo interpuesta por doña Asunción Beatriz Gracia Ponze Cuba contra los jueces integrantes de la Tercera Sala Civil de la Corte Superior de Justicia de Lima, el procurador público del Poder Judicial y el Colegio de Notarios de Lima

El proceso pretendía que se declarase la nulidad de resoluciones judiciales dictadas en un proceso de amparo que habían determinado que se reponga un proceso contencioso 
administrativo incoado por la demandante contra el Consejo del Notariado para lograr una reubicación de su plaza notarial, bajo el concepto - no admitido por la ley- de "reunificación familiar", a fin de que se emplace debidamente al Colegio de Notarios de Lima en virtud de su legitimidad material y procesal. Sobre este tema, vale la pena citar a Pondé (1977), que lo esclarece completamente:

c) Traslado.

Funcionario público: Es evento de persistente posibilidad; por razones de necesidad de servicio o por turbio manejo político, el hecho es que el traslado es factible.

Notario: Es imposible.

Al notario se le discierne el cargo para ejercer dentro de un ámbito territorial preestablecido y no puede ser trasladado a ningún lugar. (p. 347)

Si bien la demanda fue desestimada por el Tribunal Constitucional por razones de orden procesal, merece la pena resaltar la última fundamentación de este órgano jurisdiccional, que tiene que ver con el deber de cubrir las plazas vacantes, el cual recae tanto en los colegios de notarios como en el Consejo del Notariado y, finalmente, en el Ministerio de Justicia y Derechos Humanos:

39. Finalmente, hay una cuestión que para este Tribunal no es menor y que se vincula con el caso de autos. Al respecto, mediante Oficio 1216-2018-JUS/CN/P, de fecha 5 de julio del 2018, el Presidente del Consejo de Notariado informó a este Tribunal sobre ciertos aspectos que conciernen al mecanismo de convocatoria a concurso público de las plazas notariales vacantes. De la información remitida se advierte, en primer término, que en el Distrito Notarial de Lima existen 164 plazas notariales repartidas en 43 distritos. De estas, en la última década (2008-2018), hubo 48 plazas vacantes para ser convocadas a concurso. A la fecha, 12 de dichas plazas se encuentran pendientes de ser convocadas a concurso público, puesto que solamente fueron convocadas 5 en el Distrito Notarial de Lima en el 2018. Todo ello, pese a que según lo dispuesto por el artículo 9 del Decreto 1049, Decreto del Notariado, deben convocarse concursos públicos para cubrir todas las plazas notariales vacantes o que sean creadas; responsabilidad que recae, con plazos específicos y de forma compartida, en los colegios de notarios, en el Consejo del Notariado y en el Ministerio de Justicia y Derechos Humanos, respectivamente.

40. Así las cosas, este Tribunal considera oportuno recordar la importancia y el cuidado con el que se debe llevar a cabo el proceso de creación de las plazas notariales en todo el país, así como las convocatorias a concurso público de las mismas. Dichas tareas, que se llevan a cabo de manera articulada entre los distintos colegios de notarios, el Consejo del Notariado y el Ministerio de Justicia y Derechos Humanos, deben guiarse indefectiblemente por la transparencia, debiendo, además, cumplir cada una de dichas entidades con las funciones que la ley sobre la materia les encarga. 
Para el Tribunal Constitucional, los concursos notariales deben ser transparentes y deben cubrirse de forma oportuna las plazas vacantes, tal como lo señala el artículo 9 del Decreto Legislativo del Notariado, siendo responsabilidad apremiante de los órganos mencionados tal cumplimiento legal. No puede olvidarse que el servicio notarial es, en puridad, esencial para el desarrollo de la vida social, pues su insuficiencia afecta gravemente a los ciudadanos de nuestro país.

Sentencia de fecha 5 de marzo del 2020, recaída en el Expediente N. ${ }^{\circ}$ 00018-2015PI-TC, que declaró infundada la demanda de inconstitucionalidad interpuesta por ciudadanos contra el Congreso de la República en la que se pretendió que se declare la inconstitucionalidad del artículo 5 y Primera Disposición Complementaria y Modificatoria de la Ley N. ${ }^{\circ} 30313$

Esta sentencia, si bien declaró infundada la pretensión, determinó como criterios interpretativos que los extremos cuestionados del artículo 5 y de la Primera Disposición Complementaria y Modificatoria de la Ley N ${ }^{\circ} 30313$ son constitucionales en tanto se considere que, para la configuración de la buena fe del tercero, se debe haber desplegado una conducta diligente y prudente, desde la celebración del acto jurídico hasta la inscripción del mismo, además de haber dado pleno cumplimiento a todos los requisitos establecidos en el artículo 2014 del Código Civil, modificado por la Ley N. ${ }^{\circ}$ 30313; así como que la aplicación en una decisión judicial del artículo 2014 del Código Civil, modificado por la Ley $\mathrm{N}^{\circ}{ }^{\circ} 30313$, en caso de que el propietario original haya sido víctima de falsificación de documentos y suplantación de identidad y se encuentre en situaciones de especial vulnerabilidad que hayan dificultado el cumplimiento de su deber de diligencia, como puede ser la precariedad de su situación socioeconómica, educativa, cultural o cualquier otra desventaja objetiva de similar índole, requiere de una motivación cualificada.

Como sin duda recordamos, la demanda pretendía que no fueran considerados como supuestos aplicables a las situaciones de invulnerabilidad del tercero registral los casos en que se había afectado el derecho de propiedad del titular mediante un fraude documentario o una suplantación de identidad. El Tribunal Constitucional considera que sí resulta de aplicación el artículo 2014 del Código Civil a estos supuestos, pues regula de forma rigurosa los estándares de comportamiento del tercero, e impone al juez el deber de considerar la situación de vulnerabilidad del propietario perjudicado, en relación con el deber de diligencia que le corresponde a efectos de exteriorizar su derecho de propiedad, sea mediante la conducta posesoria o recurriendo a los mecanismos registrales que el sistema le faculta, tales como la alerta registral, por ejemplo.

Respecto a la función notarial propiamente dicha, en esta sentencia el Tribunal Constitucional tiene palabras breves, pero contundentes. En el fundamento 37 de la 
resolución comentada, se indica lo siguiente: "[E]l correcto funcionamiento del sistema registral exige de parte de los notarios, árbitros, jueces y registradores un adecuado ejercicio de sus funciones y deberes de especial diligencia [...]". Conviene citar aquí al jurista peruano Gonzales Barrón (2013):

[...] el notario es garante de la seguridad, pero también y de manera irrenunciable, debe serlo de la justicia, por tanto, no basta dar fe del acuerdo, pues resulta necesario que el notario asegure la igualdad real de los contratantes, para lo cual debe realizar las siguientes actividades: brindar adecuada asesoría conforme a la legalidad, advertir cláusulas abusivas o situaciones irregulares (fines dudosos, futuros problemas jurídicos, falta de prueba de la propiedad del vendedor, etc.), adecuar la voluntad de las partes al fin pretendido, entre otras. (p. 120)

Y en los fundamentos 70 al 72 el Tribunal Constitucional determina lo siguiente:

70. [...] En primer lugar, con respecto a los notarios, el Decreto Legislativo 1049, "Decreto Legislativo del Notariado" y sus modificatorias han establecido los supuestos en los cuales estos son responsables en sede administrativa (artículo 144), en sede civil y en sede penal (artículo 145). Asimismo, los tres tipos de responsabilidad pueden concurrir de forma simultánea, toda vez que, en virtud del artículo 146 del citado Decreto Legislativo, cada uno de ellos es independiente.

71. De esta manera, se observa sobre el particular que en el ordenamiento jurídico peruano se cuenta con disposiciones sobre la responsabilidad de los notarios. Sin embargo, no puede perderse de vista que toda regulación sin una adecuada aplicación no puede cumplir los fines que le son ínsitos.

72. En ese sentido, el Tribunal de Honor y el Consejo del Notariado deberán sancionar ejemplarmente la conducta de los notarios que dolosamente o por negligencia afecte el derecho de propiedad.

Esta exigencia que el Tribunal Constitucional impone al Tribunal de Honor y al Consejo del Notariado sin duda será tomada en cuenta por los órganos a cargo de la disciplina de la función notarial, remarcando que se exige la ejemplaridad de la sanción (léase gravedad) tanto en los supuestos de dolo como en los de negligencia, de lo que habrá que tomar debida cuenta. Para Cosola (2010), la responsabilidad disciplinaria del notario tiene "un carácter docente y fundamentalmente tiende a conservar la salud de todo el cuerpo colegiado" (p. 128). Este autor precisa que la aplicación de dicha disciplina permite la depuración de los que lo dañan y la demostración ante la sociedad de que las instituciones que ejercen la disciplina en el gremio notarial no buscan defender a sus colegiados, sino ser transparentes en la defensa de los ciudadanos (p. 129). 
Sentencia de fecha 7 mayo del 2020, recaída en los Expedientes N. $.^{\circ} 00003-2016-P I-$ TC y 00006-2016-PI-TC (acumulados), que declara infundadas las demandas de inconstitucionalidad planteadas por el Colegio de Notarios de San Martín y el Colegio de Notarios de Lima contra el Poder Ejecutivo

Las demandas pretendían que se declarase la inconstitucionalidad por la forma de la totalidad del Decreto Legislativo N. ${ }^{\circ} 1232$; y, por el fondo, del artículo 1 de dicha norma, en cuanto modifica el artículo 137 del Decreto Legislativo del Notariado; de los artículos 1 y 2, en cuanto modifican los artículos 149, 150 y 152 del Decreto Legislativo del Notariado; y la incorporación de los artículos 149-A, 149-B y 149-C.

En cuanto a la inconstitucionalidad por la forma de todo el Decreto Legislativo N. ${ }^{\circ} 1232$, el Tribunal Constitucional considera que este no excede el ámbito de la delegación legislativa permitida por la Ley $\mathrm{N}^{\circ}$ 30336, por el término de noventa días calendario en materia de seguridad ciudadana, lucha contra la delincuencia y contra el crimen organizado. Señala el tribunal, en su fundamento 18, que la norma cuestionada "alude a una problemática concreta, como es la comisión de fraudes y hechos delictivos vinculados con el registro y transferencia de predios, en un contexto de inseguridad ciudadana".

Entre otras consideraciones, en el fundamento 21, se indica que "el correcto ejercicio de la función notarial es un requisito indispensable para la optimización del sistema nacional de registros públicos". Y, si bien se puede discrepar de si las opciones legislativas son las más correctas para el fin propuesto, hay que concordar en que, en el esquema de seguridad jurídica preventiva, propia de los países tributarios del derecho civil de inspiración latina, la función notarial cumple un papel preponderante para garantizar la certeza y la ausencia de conflicto en las transacciones que se formalizan en los instrumentos públicos.

Respecto a la modificación del artículo 137 del Decreto Legislativo del Notariado, en cuya nueva redacción se estableció que la presidencia del Consejo Directivo de la Junta Nacional de los Decanos de los Colegios de Notarios del Perú debía recaer siempre en el decano del Colegio de Notarios con mayor número de agremiados (es decir, el de Lima por obvias razones), en su fundamento 33, el Tribunal Constitucional determinó:

[L]a Junta de Decanos es un órgano de coordinación de los Colegios de Notarios de la República, cuyo desarrollo tiene rango legal y no constitucional. En efecto, se trata de un órgano creado por la ley y no por los colegios profesionales de los notarios en el ejercicio de su autonomía.

Por esta razón, en el fundamento 35 excluye a este órgano de la protección que el artículo 20 de la Constitución concede a los colegios profesionales en cuanto instituciones autónomas de derecho público.

Debemos denunciar este razonamiento como profundamente incorrecto. La Junta de Decanos no expresa simplemente una voluntad legislativa, pues, al ser un órgano que 
ejerce la representación del notariado en el ámbito internacional (artículo 135), responde a la voluntad de los Colegios de Notarios de la República, representados en su oportunidad por sus respectivos decanos. No olvidemos que el presidente de dicho órgano es la cara visible del Perú en la Unión Internacional del Notariado Latino, y esta incorrecta interpretación del Tribunal Constitucional abre la puerta a intromisiones del poder en el ámbito de la autonomía del notariado en materia de la designación de sus representantes. Esto ya sucedió en el pasado, cuando por el Decreto Supremo N. ${ }^{\circ}$ 002-97-JUS de fecha 17 de marzo de 1997 se removió al entonces presidente de la Junta de Decanos, y este mismo tribunal dictó sentencia con fecha 8 de agosto de 1998, recaída en el Expediente N. ${ }^{\circ}$ 0456-1998-AA, sobre la acción de amparo interpuesta por don Carlos Enrique Becerra Palomino, ordenando su reposición, por considerar que se violó la autonomía de los colegios profesionales consagrada en el artículo 20 de la Constitución.

Es, pues, lamentable que la sentencia que reseñamos se haya apartado de la anterior línea jurisprudencial, y esperemos que no se lesione en ulterior oportunidad la autonomía de la Junta de Decanos de los Colegios de Notarios del Perú, tal como se hizo en el Decreto Legislativo N. ${ }^{\circ} 1232$.

Finalmente, con respecto al nuevo régimen de infracciones establecido en los artículos 149, 149-A, 149-B y 149-C, 150 y 152 del Decreto Legislativo del Notariado, el Tribunal Constitucional considera que dichas normas cumplen los parámetros de legalidad, tipicidad y proporcionalidad, recordando en su fundamento 66 lo siguiente:

[...] independientemente de la modificación de los artículos 149 y 150 del Decreto Legislativo del Notariado, existen instrumentos normativos y jurisprudenciales vinculantes de observancia obligatoria para la aplicación de sanciones disciplinarias administrativas a los notarios que evitan que estos últimos sean objeto de una sanción arbitraria.

Estos instrumentos son las propias decisiones del Tribunal Constitucional en casos resueltos en los que se obtuvo protección constitucional contra decisiones arbitrarias de la administración pública en materia disciplinaria.

\section{COLOFÓN}

Sin duda, las decisiones del Tribunal Constitucional deben ser tomadas en cuenta por los notarios, en cuanto se trate de temas vinculados con el ejercicio de su función. Recordemos que el propio Decreto Legislativo del Notariado obliga al notario a orientar su actuar profesional y personal en el respeto a la Constitución y las leyes. Ese es nuestro compromiso, y más allá de discrepar en algún caso con algún criterio interpretativo de dicho órgano de la justicia constitucional, renovamos nuestro propósito de seguir siendo lo que somos: personas de carne y hueso que amamos el Derecho con mayúsculas y que servimos a todas las personas, sin exclusión alguna. 


\section{REFERENCIAS}

Arias Montoya, 0. (2011). Comentarios a la actualidad notarial peruana. Lima: Gaceta Notarial.

Becerra Palomino, C. E. (2015). El honor de dar fe. Lima: Editorial Jurídica del Perú.

Cosola, S. J. (2010). Los fundamentos éticos del derecho notarial. Lima: Gaceta Notarial.

Giménez Arnau, E. (1976). Derecho notarial. Pamplona: Universidad de Navarra.

Gonzales Barrón, G. (2013). El notario es agente de la libertad real. En L. B. Pérez Gallardo y M. A. Arévalo (Coords.), Escritos sobre derecho notarial. Libro homenaje a Carlos Enrique Becerra Palomino (pp. 95-123). Lima: Gaceta Notarial.

Peralta Castellano, J. (2013). Algunos temas notariales sobre la nacionalidad y la identidad. En L. B. Pérez Gallardo y M. A. Arévalo (Coords.), Escritos sobre derecho notarial. Libro homenaje a Carlos Enrique Becerra Palomino (pp. 247-269). Lima: Gaceta Notarial.

Pondé, E. B. (1977). Tríptico notarial. Buenos Aires: Depalma.

Sanahuja y Soler, J. M. (1945). Tratado de derecho notarial (vol. II). Barcelona: Bosch.

Sentencia recaída en el Expediente N. ${ }^{\circ}$ 06227-2013-PHD/TC. (2014). Tribunal Constitucional del Perú. Recuperado de https://tc.gob.pe/jurisprudencia/2014/06227-2013 -HD.pdf

Sentencia recaída en el Expediente N. ${ }^{\circ}$ 07977-2013-PH/TC. (2015). Tribunal Constitucional del Perú. Recuperado de https://tc.gob.pe/jurisprudencia/2016/07977-2013-HC.pdf

Sentencia recaída en el Expediente N. ${ }^{\circ}$ 03025-2014-PHD/TC. (2017). Tribunal Constitucional del Perú. Recuperado de https://tc.gob.pe/jurisprudencia/2018/03025-2014-HD.pdf

Sentencia recaída en el Expediente N. ${ }^{\circ}$ 02111-2016-PA/TC. (2018). Tribunal Constitucional del Perú. Recuperado de https://tc.gob.pe/jurisprudencia/2019/02111-2016-AA.pdf

Sentencia recaída en el Expediente N. ${ }^{\circ} 06001-2014-P A / T C . ~(2019)$. Tribunal Constitucional del Perú. Recuperado de https://tc.gob.pe/jurisprudencia/2019/06001-2014-AA.pdf

Sentencia recaída en los Expedientes N. ${ }^{\circ}$ 00003-2016-PI-TC y N. ${ }^{\circ}$ 00006-2016-PI-TC (acumulados). (2020). Tribunal Constitucional del Perú. Recuperado de https:// tc.gob.pe/jurisprudencia/2020/00006-2016-Al.pdf

Sentencia recaída en el expediente N. ${ }^{\circ} 00018-2015-P I-T C . ~(2020)$. Tribunal Constitucional del Perú. Recuperado de https://tc.gob.pe/jurisprudencia/2020/00018-2015-Al.pdf 